\title{
Os gastos das famílias com saúde
}

\author{
Families' expenses with health
}

Fernando Gaiger Silveira 1

Rafael Guerreiro Osório 2

Sérgio Francisco Piola 2

\footnotetext{
1 Diretoria de Estudos e Políticas Setoriais, Instituto de Pesquisa Econômica Aplicada. SBS Quadra 01, Edifício BNDES/IPEA. 70076-900 Brasília, DF. gaiger@ipea.gov.br 2 Diretoria de Estudos e Políticas Sociais, Instituto de Pesquisa Econômica Aplicada.
}

Abstract The article discusses the main characteristics of the Brazilian families' expenses with health, based on two different data sources: the Survey on Household Budgets (POF) and the National Survey of Sampled Households (PNAD). The importance of the expenses with health in regard to other groups of expenses is shown, as well its amount is estimated. It is demonstrated that the main categories of families' expenses with health are those related to the purchase of medicine and with the monthly fees of private health insurance. The families of the people who are amongst the $30 \%$ richest Brazilians are responsible for the majority of these expenses. In the families of the $90 \%$ poorest Brazilians, the greatest part of health expenses are due to medicine purchased. The poorest the families are, highest is the impact of the health expenses in their monthly budget, either if considering expenses with medicine, with private health insurance, or general.

Key words Expenses with health, Expenses with medicine, Expenses with private health insurance fees; families
Resumo $O$ artigo discute as principais características dos gastos das famílias brasileiras com saúde, a partir de duas fontes distintas: a Pesquisa de Orçamentos Familiares (POF) e a Pesquisa Nacional por Amostra de Domicílios (PNAD). Mostra-se a importância do gasto com saúde em relação aos outros grupos de despesas, e se procede à estimativa do montante destes gastos. No artigo, apontam-se as duas principais categorias do gasto das famílias com saúde: os medicamentos e as mensalidades de planos ou seguros de saúde. As famílias das pessoas que estão entre os $30 \%$ mais ricos são as responsáveis pela maior parte dos gastos totais. Nas famílias das pessoas que pertencem aos $90 \%$ mais pobres da população, a maior parte dos dispêndios com saúde se dirige à compra de medicamentos. Quanto mais pobres são as famílias consideradas, maior é o peso, entendido como porcentagem da renda familiar, representado pelos gastos com medicamentos, planos e com saúde em geral.

Palavras-chave Gastos com saúde, Gastos com medicamentos, Gastos com planos de saúde, Famílias 


\section{Os gastos das famílias com saúde}

Neste artigo, busca-se descrever de forma sucinta quais são as principais características dos gastos das famílias com saúde no Brasil. As famílias devem ser a unidade de análise privilegiada por excelência em um estudo como este, pois as decisões sobre o empenho dos recursos angariados pelos indivíduos nos dispêndios com saúde raramente são estritamente individuais. Decisões sobre a aquisição de planos de saúde, de medicamentos, de tratamentos dentários, de óculos e gastos afins têm, para a maior parte da população, um impacto significativo no orçamento doméstico, e muitas vezes pode implicar a participação de membros da família que não residem no mesmo domicílio. Filhos zelosos podem ajudar a custear os medicamentos de uso regular indispensáveis à saúde de pais idosos que com eles não coabitam, da mesma forma que os avós podem eventualmente pagar pelo plano de saúde dos netos. Infelizmente, devido às limitações impostas pelas fontes de dados utilizadas, não é possível captar toda a rede familiar que pode estar envolvida nas decisões sobre os gastos com saúde. Portanto, faz-se necessário ater-se à parcela da estrutura familiar que coabita em um domicílio, e que provavelmente decide "coletivamente" sobre a oportunidade e a necessidade deste tipo de gasto.

Em um primeiro momento, buscar-se-á quantificar o volume e o tipo dos dispêndios em saúde. O objetivo é fornecer uma estimativa de quanto gastam anualmente com saúde as famílias brasileiras, e com o quê. Como se espera de antemão que os gastos das famílias mais pobres sejam quantitativa e qualitativamente distintos dos das famílias mais ricas, uma escala de pobreza relativa, décimos da renda domiciliar per capita, será utilizada para que se possa caraterizar a dimensão dessas diferenças. Em um segundo momento, os dispêndios totais com saúde e as suas duas principais categorias, os gastos com medicamentos e com planos de saúde, serão analisados a respeito de seu impacto na renda das famílias. Em outras palavras, serão fornecidas estimativas da porcentagem da renda das famílias que é empenhada em gastos com saúde. Mais uma vez, essas estimativas levarão em conta a situação socioeconômica das famílias, aproximada pela escala de pobreza relativa anteriormente citada.

Existem, basicamente, duas fontes de dados que permitem o estudo dos gastos das famílias com saúde: uma é a Pesquisa de Orçamentos Fa- miliares (POF), realizada pelo IBGE em 1995/96 nas nove regiões metropolitanas, em Brasília, e no município de Goiânia. A POF é uma pesquisa detalhada sobre como as famílias adquirem e gastam os seus recursos, não só com saúde, mas todas as classes de despesas, da alimentação ao transporte, passando pelo vestuário, pelo lazer e mesmo pelos impostos. A POF permite dimensionar o peso do gasto com saúde em relação aos demais dispêndios familiares. A segunda fonte de dados é a Pesquisa Nacional por Amostra de Domicílios (PNAD), que é realizada anualmente, também pelo IBGE, em todo o território nacional, exceto nas áreas rurais da Região Norte, onde a densidade habitacional é baixíssima. Em 1998, a PNAD foi realizada com um suplemento especial dedicado a vários aspectos da saúde, entre eles os gastos dos indivíduos agrupados em várias categorias, como medicamentos de uso regular, mensalidades de planos de saúde e consultas médicas, dentre outros. Entretanto, a PNAD não contempla informações sobre outros tipos de gasto (como habitação, transporte, alimentação, entre outros).

As informações providas pela PNAD e pela POF não são rigorosamente comparáveis, não só pelas diferentes coberturas territoriais, mas também pela forma de captação. Entretanto, no que toca aos gastos com saúde, o panorama geral delineado pelas duas pesquisas é extremamente semelhante, como será visto adiante, razão pela qual utilizam-se as informações de ambas apresentadas em perspectiva comparada. Antes de se passar aos resultados, porém, é preciso fazer algumas considerações de ordem metodológica sobre o tratamento dado às informações de ambas as pesquisas para que o grau de comparabilidade entre elas se tornasse um pouco mais elevado. Aproveita-se o ensejo para tecer comentários um pouco mais aprofundados sobre as características da POF e da PNAD, e sobre a qualidade e as limitações das informações sobre o gasto com saúde providas por uma e por outra.

\section{A captação do gasto em saúde na POF e na PNAD}

Estimar as dimensões do mercado consumidor para determinados grupos de produtos e serviços, como, dentre outros, os de saúde, é uma das principais aplicações da POF, pesquisa que mede, "a partir de amostras representativas da 
população-objetivo, as estruturas dos gastos, receitas e poupança das famílias" (Brasil, 1999). A POF é uma descendente direta do Estudo Nacional das Despesas Familiares (Endef), uma pesquisa pioneira realizada em todo o Brasil em meados da década de 1970 . A primeira edição da POF foi realizada em 1987/88, com a mesma abrangência geográfica da de 1995/96 que será utilizada como fonte das informações apresentadas, ou seja, as nove regiões metropolitanas (Belém, Fortaleza, Recife, Salvador, Belo Horizonte, Rio de Janeiro, São Paulo, Curitiba e Porto Alegre), mais Brasília e Goiânia.

A principal característica da POF é o elevado nível de detalhe na captação das despesas familiares. Além das despesas, as POFs também captam detalhadamente a composição dos rendimentos domiciliares. Sua confiabilidade e qualidade são comprovadas, tanto que as POFs são utilizadas como base para a determinação das estruturas de ponderação de alguns dos principais índices de preços utilizados no Brasil, como o INPC e o IPCA, ambos calculados e divulgados pelo próprio IBGE. Outra utilização importante da POF tem sido no estabelecimento de cestas mínimas de consumo que embasam algumas das linhas de pobreza brasileiras calculadas em trabalhos recentes (Rocha, 2000).

A captação das informações pela última edição divulgada da POF ocorreu durante um ano, de primeiro de outubro de 1995 a 30 de setembro de 1996, tendo sido o dia 15 de setembro de 1996 arbitrado como data de referência. Nesse dia, o valor do salário-mínimo era de 112 reais. Cada domicílio pesquisado teve seu orçamento acompanhado por um período de nove dias (os dois primeiros para estabelecer um contato mais aprofundado, e os restantes para o registro de despesas), e suas informações captadas por intermédio da utilização de cinco instrumentos de registro: um para coletar as características gerais da unidade domiciliar e dos residentes (POF 1); outro para as despesas coletivas do domicílio e para o inventário de bens duráveis (eletrodomésticos) disponíveis (POF 2); uma caderneta de despesas coletivas, que serve para o registro, no momento da compra, das despesas com alimentação, artigos de higiene pessoal, material de limpeza e pequenas compras (POF 3); um questionário detalhado para o registro das despesas individuais (POF 4), no qual são registrados os gastos com saúde; e um questionário para captar os recebimentos individuais (POF 5). A POF possui quatro períodos de referência relativos para a captação de informações sobre despesas e recebimentos, aplicáveis, dependendo da natureza destes, sete dias, trinta dias, noventa dias e seis meses.

O questionário de despesa individual registra, para cada membro do domicílio, vários grupos de despesas, entre eles alguns que representam gastos com saúde. O primeiro diz respeito aos gastos com produtos farmacêuticos nos trinta dias anteriores à entrevista. São registrados os gastos com medicamentos em geral, independentemente de serem ou não de uso regular, de analgésicos a fortificantes, passando por vasodilatadores e anticoncepcionais. Também são registradas as despesas com outros produtos farmacêuticos, como seringas, material para curativos, mamadeiras, etc. A POF permite a inclusão de itens de despesas que não estavam originalmente previstos nos questionários. É importante notar também que, muitas vezes, as despesas registradas para um morador podem se referir a produtos comprados para outro morador, ou mesmo para um não residente. Assim, por exemplo, as despesas com a compra de medicamentos para crianças provavelmente serão registradas na conta de um de seus pais. Daí a importância de se considerarem as famílias como unidade de análise.

São registrados também os gastos com serviços variados de assistência à saúde realizados no período de 90 dias antes da data da entrevista. Essas despesas compreendem tratamentos, próteses e aparelhos dentários; consultas com médicos e outros profissionais de saúde, e mesmo com curandeiros e curiosos; seguros e planos de saúde e mensalidades clínicas etc. Embora o grau de detalhamento na captação das informações seja elevado, o plano tabular da POF utilizado nas publicações e no banco de dados agregado do IBGE (Sidra) é pouco detalhado e aglutina uma quantidade enorme de despesas díspares sob rubricas genéricas (outros). A utilização dos microdados (informações, questionário por questionário) da POF, todavia, permite a recuperação do grau de detalhe original e o agrupamento das despesas em planos tabulares alternativos, o que é feito neste trabalho.

A PNAD, a exemplo da POF, é outra pesquisa de qualidade reconhecida, extremamente confiável, e que tem sido utilizada tanto para subsidiar o planejamento e a elaboração de políticas públicas de diversos setores, quanto em estudos sobre a situação socioeconômica geral da população brasileira por cientistas sociais de várias áreas, mas especialmente por economistas e sociólogos. Uma de suas características é a 
adição de suplementos temáticos ao corpo básico da pesquisa para o estudo de assuntos específicos, sendo que em 1981 e em 1998 o suplemento foi dedicado a questões de saúde.

No suplemento de saúde da PNAD de 1998 são inicialmente captadas informações relativas ao estado individual de saúde, seguidas por características dos planos de saúde, depois por um conjunto de questões relativas ao acesso e à utilização de serviços de saúde. Após esta bateria de questões, uma série de perguntas busca captar os gastos com saúde realizados pelos indivíduos. Esta seqüência de temas faz com que seja ampliada a qualidade das informações sobre o gasto, pois as perguntas anteriores fazem com que os entrevistados se lembrem dos problemas de saúde que tiveram e dos serviços procurados e utilizados, e, por conseguinte, se representaram despesas e o montante destas.

É importante notar que os gastos realizados pelos indivíduos não necessariamente se referem à própria saúde, pois um indivíduo pode pagar pelas despesas de saúde de outro morador do domicílio, ou mesmo de pessoas que não residam no domicílio (Brasil, 1998). Mais uma vez, a exemplo da POF, tal fato ressalta a importância de se considerar a família como instância do gasto com saúde. No caso da PNAD, considera-se neste trabalho a família como sendo equivalente ao grupo de pessoas que coabitam em uma unidade domiciliar. Para uma discussão mais aprofundada sobre os conceitos de família e domicílio nas PNADs, vide Medeiros et al. (2002).

Relembra-se que as crianças têm as informações dos seus gastos acumuladas nos gastos dos pais, ou de outros adultos, que pagaram suas despesas com saúde. Todos os gastos captados pela PNAD representam desembolsos efetivos, isto é, incluem eventuais multas, juros e outros encargos, e excluem quaisquer abatimentos ou descontos que tenham ocorrido. Seguindo a mesma lógica, se houve reembolso do gasto por parte do plano de saúde ou do empregador, por exemplo, somente a parte efetivamente arcada pelo indivíduo é registrada, caso o reembolso não tenha sido integral. Entretanto, se o reembolso ainda não tiver sido requerido ou efetivado, o gasto é integralmente registrado.

Os períodos de referência da PNAD normalmente se referem a uma data fixa, entretanto, no suplemento de saúde, os períodos são relativos, isto é, referem-se a um intervalo de tempo anterior à data de realização da entrevista. No caso dos dispêndios com saúde, são utiliza- dos dois períodos de referência para a captação dos gastos, dependendo da categoria: um mês antes da data da entrevista; e três meses antes da data de entrevista. Assim, por exemplo, se um atendimento de saúde, como uma consulta médica, ocorre dentro do período de referência, mas é pago com um cheque pré-datado (ou com cartão de crédito) cuja data para depósito é posterior à data da entrevista, o gasto relativo a ela não será registrado. A maior parte dessas observações sobre a forma de registro dos gastos vale também para a POF.

Os gastos com saúde são captados segundo 11 categorias distintas. O primeiro tipo de gasto averiguado é o efetuado com medicamentos de uso permanente, alopáticos ou homeopáticos, independentemente da forma de administração. Somente o total deste gasto é registrado, não sendo possível distinguir a finalidade, quantidade ou o tipo de medicamento que foi adquirido, nem quais os moradores do domicílio (ou se se destinam a não residentes) que deles fazem uso. Os gastos com medicamentos de uso permanente são os únicos captados no período de referência de 30 dias antes da data da entrevista.

Todos os demais gastos são captados tendo como referência o período relativo de três meses. Primeiramente são registrados os gastos trimestrais com mensalidades de planos ou seguros de saúde ou de clínicas. Depois são captados os dispêndios com consultas médicas. As despesas realizadas com outros profissionais de saúde, como fisioterapeutas, nutricionistas, psicólogos e congêneres são registradas em uma rubrica à parte. Outra categoria agrega os gastos efetuados com internações hospitalares, dos honorários médicos às eventuais despesas dos acompanhantes. Os dispêndios trimestrais efetuados com enfermagem domiciliar são registrados em uma categoria particular. Quaisquer exames laboratoriais, da imagenologia à patologia clínica, que tenham sido pagos no período de referência são somados em outra categoria de gasto. Os valores gastos com tratamentos dentários, incluindo as consultas odontológicas, próteses e aparelhos são totalizados em uma categoria específica. Os gastos com óculos (armações e lentes) e lentes de contato cuja utilização tenha sido prescrita por oftalmologista são armazenados em outra categoria (mas não as consultas com esses profissionais médicos). Outra categoria agrega todos os gastos eventualmente realizados com a aquisição ou aluguel de aparelhos ou artigos médicos e ortopédicos, como 
botas, palmilhas, muletas, cadeiras de rodas, nebulizadores, camas hospitalares, aparelhos auditivos, marca-passos, etc. Finalmente, há uma categoria para registrar os gastos com próteses (exceto as dentárias), pernas, braços ou mãos mecânicas, mamárias, etc.

O grande grau de detalhe na captação das informações, tanto na PNAD quanto na POF, faz com que algumas categorias de gastos existam em apenas uma pequena parcela dos domicílios da amostra. Assim, o estudo do gasto em uma perspectiva abrangente acaba por exigir uma agregação das categorias que são menos representativas de um ponto de vista estritamente quantitativo. No caso do presente estudo, como se tenciona empreender uma comparação dos dados de duas fontes, a POF e a PNAD, a agregação se torna imperativa por aumentar a comparabilidade, que se tornaria inviável em um nível de detalhe extremado. Portanto, no caso da PNAD, as 11 categorias de gasto foram reagrupadas em seis categorias. $\mathrm{O}$ mesmo foi feito com a POF, sendo que nesta partiu-se de um plano tabular alternativo, buscando obter-se categorias mais comparáveis com as da PNAD. Ainda assim, convém ressaltar, mais uma vez, que as categorias utilizadas são apenas aproximadamente semelhantes.

Outro aspecto imperativo é a anualização do gasto captado, para a compatibilização dos diferentes períodos de referência, e a mensalização, quando se deseja estimar o peso dos dis- pêndios com saúde em relação à renda domiciliar. Quanto à renda domiciliar, cabe lembrar aqui que pesquisas domiciliares estão sujeitas a problemas de subnotificação da renda por parte dos entrevistados, e que geralmente a captação é pior para a parcela mais rica da população. Isto faz com que as rendas totais obtidas a partir das rendas domiciliares declaradas sejam menores do que a obtida por outras estimativas, como as contas nacionais (Hoffmann, 1998). É importante ressalvar também que, devido às formas distintas de captação e amostragem, as rendas totais das regiões metropolitanas obtidas na PNAD podem diferir das da POF (Barros et al., 1995). No entanto, dado o tipo de análise que será conduzida, este problema não constitui um óbice efetivo para o presente estudo.

\section{A dimensão dos gastos com saúde}

As informações providas pela POF permitem avaliar a dimensão das despesas com saúde em relação a outros tipos de despesa das famílias. Do total desembolsado pelas famílias representadas pela POF de 1995/96, 81\% foram destinados a despesas correntes, $17 \%$ ao aumento do ativo, e os restantes $2 \%$ à diminuição do passivo. Das despesas correntes, $88 \%$ eram despesas de consumo (71\% do desembolso global). A figura 1 representa a distribuição das despesas de consumo segundo vários grupos. O gas-

Figura 1

Porcentagem das despesas de consumo das famílias. Regiões metropolitanas, Brasília e Goiânia, 1995/96.

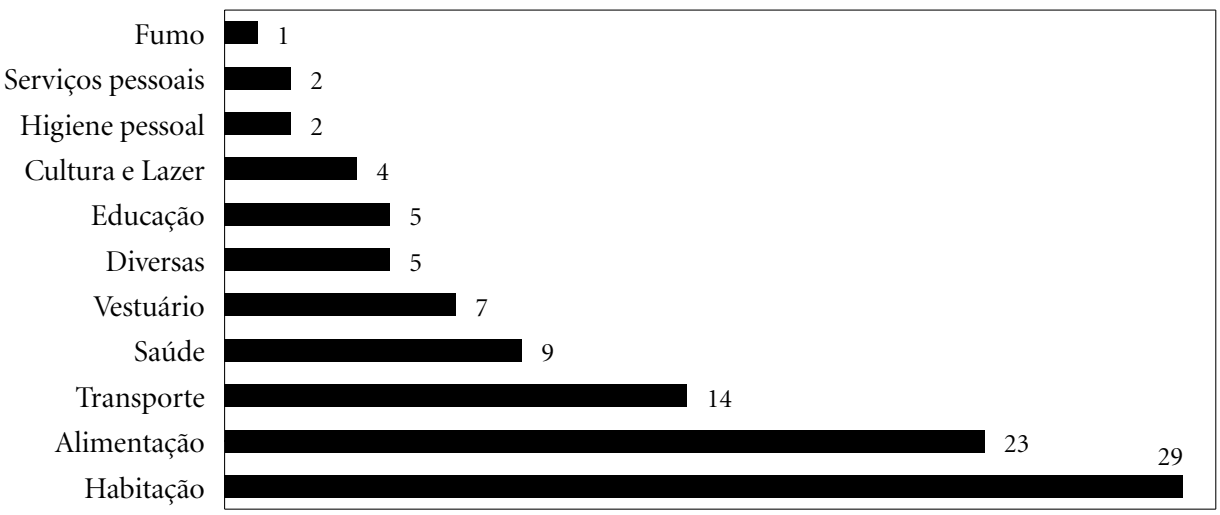

Fonte: IBGE, Pesquisa de Orçamentos Familiares 1995/96. Em microdados. 
to com saúde representava então $9 \%$ dessas despesas (7\% do desembolso global), sendo o quarto maior grupo de dispêndios familiares, atrás apenas dos gastos com habitação, alimentação e transporte. Esta colocação indica de forma expressiva o peso dos gastos com saúde no consumo das famílias. Nunca é demais lembrar que a população representada pela POF equivalia, em 1996, a 30\% da população brasileira, e a $38 \%$ da população brasileira urbana.

A partir das informações providas pela PNAD e pela POF, é possível estimar o montante dos gastos com saúde das famílias. Como a POF não tem cobertura nacional, para tornar os dados compatíveis com os da PNAD, que cobre quase todo o território nacional exceto a área rural dos estados da região Norte (menos Tocantins, cuja área rural é coberta), foi necessário realizar um exercício de nacionalização da POF. Para tanto, primeiramente, foram calculados os coeficientes de elasticidade em relação à renda dos gastos em saúde, considerando três hipóteses de diferenças de elasticidade entre estratos de renda familiar, para cada uma das nove regiões metropolitanas, Brasília e Goiânia. Em segundo lugar, foram utilizadas as informações de renda da PNAD, agrupadas segundo os mesmos estratos de renda usados para o cálculo dos coeficientes de elasticidade, e segundo combinações do tipo de área - metro- politana, não metropolitana, rural e urbana para estimar quanto seria o montante dos gastos com saúde em uma hipotética POF nacionalizada (para uma descrição detalhada da metodologia utilizada, vide Silveira et al., 2001). Além disso, o valor final obtido foi inflacionado pelo INPC-A/Saúde para valores de setembro de 1998, mês de referência da PNAD desse ano.

O resultado dessa estimativa foi muito bom, sendo extremamente próximo ao obtido pela simples soma de todos os gastos com saúde captados pela PNAD/1998, algo que depõe a favor da qualidade das informações providas por ambas as pesquisas acerca desse tipo de gasto. Pela PNAD, o total dos gastos seria de R $\$ 37.852,9$ milhões, enquanto pela nacionalização da POF seria de $\mathrm{R} \$ 36.801,7$ milhões, ou seja, apenas 3\% menor que o da PNAD.

Essas estimativas do montante total de gastos com saúde podem ser decompostas segundo algumas categorias selecionadas, para avaliar quais são os tipos de dispêndios que têm maior peso em sua composição. Os percentuais relativos a cada categoria, tanto na POF nacionalizada quanto na PNAD, estão representados na figura 2 .

Convém lembrar mais uma vez que as categorias da POF e da PNAD representadas na figura 2 não são estritamente comparáveis. Mesmo assim, é surpreendente o elevado grau de

Figura 2

Porcentagem das despesas de saúde das famílias - Brasil, 1995/96; 1998.

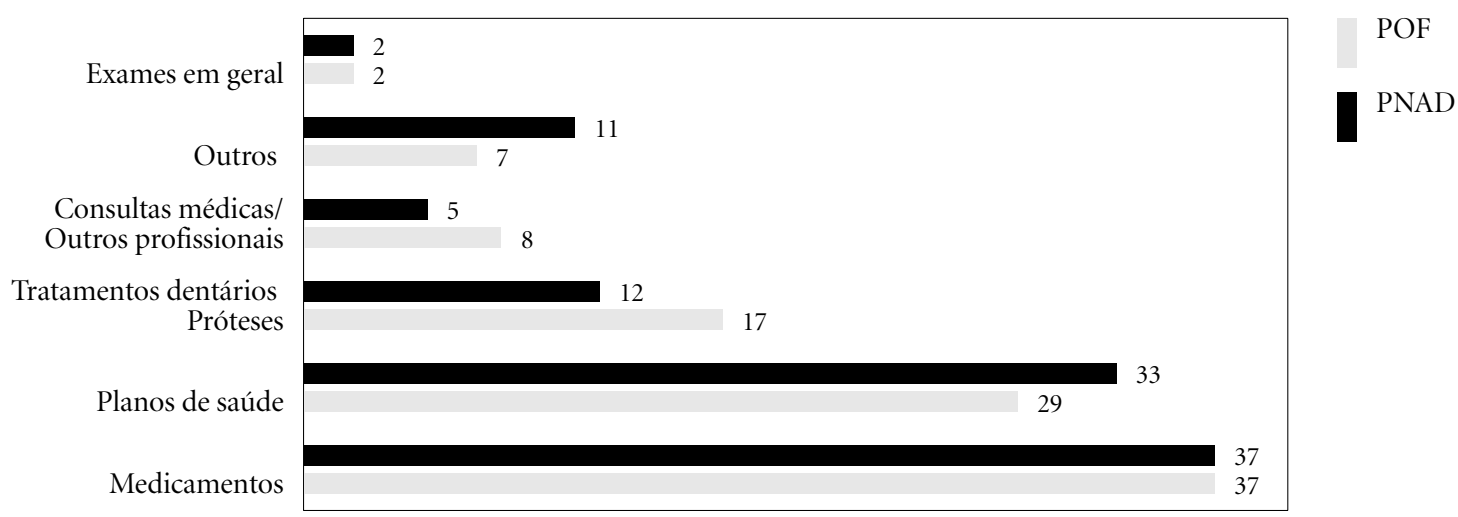

Fonte: IBGE, Pesquisa de Orçamentos Familiares 1995/96, Pesquisa Nacional por Amostra de Domicílios, 1998. Em microdados. Nota: Os dados da POF foram nacionalizados. 
coincidência entre os percentuais de cada categoria de gasto com saúde nas duas pesquisas. Os gastos com medicamentos são, em ambas as pesquisas, os de maior peso no gasto total, representando quase dois quintos deste. Ressalvase que, no caso da PNAD, esta categoria agrega apenas os gastos com medicamentos de uso regular (alopáticos ou homeopáticos), enquanto na POF representa os gastos com todos os tipos de medicamentos.

A segunda categoria de maior peso é formada pelos gastos com mensalidades de planos, seguros de saúde e de clínicas. Nesta categoria uma pequena diferença é registrada entre o percentual obtido a partir da POF nacionalizada e o verificado na PNAD, sendo o primeiro $12 \%$ menor que o último. Parte dessa diferença pode ser entendida como um efeito da expansão recente do mercado de planos e seguros de saúde, pois dois anos separam a POF da PNAD. Esta hipótese explicaria, de quebra, também a menor porcentagem dos gastos com consultas médicas na PNAD. A despeito dessa diferença, o importante é a constatação de que medicamentos e planos de saúde representam a maior parte dos gastos com saúde das famílias brasileiras, 70\% segundo a estimativa da PNAD, ou $66 \%$, na estimativa da POF nacionalizada.

Quanto às diferenças nas outras categorias de gasto com saúde, é importante lembrar que os resultados da POF são obtidos a partir do exercício de nacionalização, que tem por base os coeficientes de elasticidade do gasto com saúde calculados a partir do gasto observado nas regiões metropolitanas. Assim, o maior peso das categorias de tratamentos dentários e de consultas médicas na POF pode se dever, em parte, ao fato de que a pesquisa cobre somente as regiões metropolitanas. Como a PNAD também capta esses gastos em zonas rurais e em áreas urbanas não metropolitanas, nas quais o acesso a profissionais de saúde é mais reduzido, é de se esperar que a porcentagem correspondente aos gastos com tratamentos dentários e consultas médicas na PNAD seja ligeiramente menor que na POF. Note-se, entretanto, que a proporção dos gastos com exames em geral é praticamente idêntica nas duas pesquisas. A diferença na categoria “outros” pode ser encarada como um produto esperado dos efeitos de composição dos pesos das demais categorias de gasto.

Ordenando-se a população de forma ascendente segundo a renda domiciliar per capita, ou seja, dos mais pobres para os mais ricos, e divi- dindo-a em 10 grupos de igual tamanho, obtémse uma classificação de pobreza relativa. Nessa classificação, o primeiro estrato, ou décimo da população, corresponde aos $10 \%$ mais pobres, e, o último, aos 10\% mais ricos. Aplicando-se a classificação à POF e à PNAD, é possível estudar a diferença da composição dos gastos com saúde desses grupos que representam situações socioeconômicas distintas. A partir deste ponto, volta-se a trabalhar com os dados da POF não nacionalizada, ou seja, com as informações relativas aos gastos das famílias das nove regiões metropolitanas, Brasília e Goiânia.

A figura 3 mostra a contribuição dos gastos de cada décimo da população, ordenada dos mais pobres para os mais ricos, para a composição do gasto total em saúde. Inicialmente, nota-se mais uma vez a extrema semelhança entre os resultados obtidos a partir da POF e os da PNAD. Como seria de se esperar, os gastos dos $10 \%$ mais ricos da população (o último décimo) representam uma parcela expressiva dos gastos totais com saúde, enquanto os gastos dos $10 \%$ mais pobres constituem uma ínfima fração. Os 30\% mais ricos da população haviam sido responsáveis por $73 \%$ dos dispêndios em saúde, segundo a PNAD, e por $68 \%$, de acordo com a POF. As diferenças entre os dados da PNAD e da POF devem ser novamente entendidas como um fruto da maior cobertura geográfica da PNAD. Como esta agrega também as zonas rurais e as urbanas não metropolitanas, os 10\% mais pobres da PNAD são ainda mais pobres que o grupo equivalente determinado a partir da POF.

Os gastos dos décimos mais pobres da população são qualitativamente distintos dos gastos dos mais ricos. Enquanto entre os mais pobres a principal categoria de dispêndios com saúde são os medicamentos, à medida que os estratos mais ricos são considerados, cresce progressivamente a importância dos gastos com planos de saúde. Ainda assim, os gastos com medicamentos representam uma parcela considerável dos gastos em todos os décimos. Apenas entre os $10 \%$ mais ricos a parcela dos gastos em saúde do estrato dispendidos com planos é efetivamente superior à fração dedicada aos medicamentos. Estas considerações valem tanto para os gastos dos décimos obtidos a partir da POF quanto para os verificados pela PNAD, conforme está representado na figura 4 ( $\mathrm{a}$ e b).

Note-se, mais uma vez, que as diferenças observadas na composição percentual dos gastos de cada décimo da POF e da PNAD podem ser 
Figura 3

Porcentagem das despesas totais de saúde efetuadas para cada décimo da população

ordenada de forma ascendente pela renda domiciliar per capita. Regiões metropolitanas,

Brasília e Goiânia, 1995/96 - Brasil, 1998.

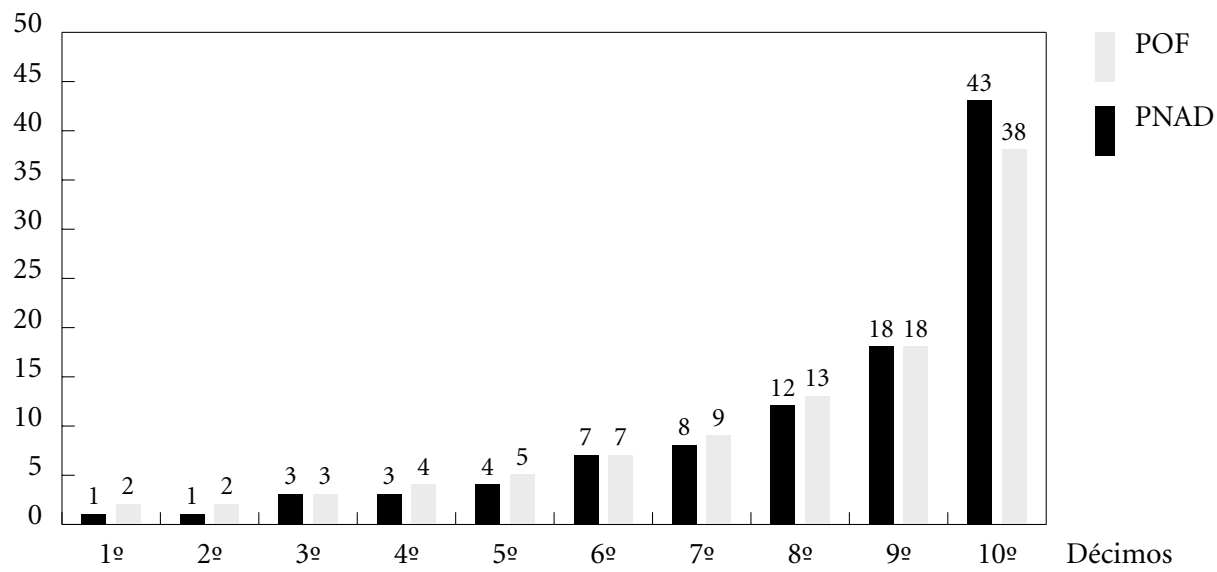

Fonte: IBGE, Pesquisa de Orçamentos Familiares 1995/96, Pesquisa Nacional por Amostra de Domicílios, 1998. Em microdados.

atribuídas às diferentes coberturas geográficas. Os décimos da POF são mais ricos que os equivalentes da $\mathrm{PNAD}$, por se referirem à população das regiões metropolitanas, sendo assim coerente o maior dispêndio em planos de saúde e o menor em medicamentos, que ocorrem, principalmente, do $4^{\circ}$ ao $8^{\circ}$ décimo.

\section{O peso dos gastos com saúde no orçamento das famílias}

$\mathrm{Na}$ seção anterior foram fornecidas estimativas do gasto total anual em saúde efetuado pelas famílias, o peso desse gasto comparado ao de outras despesas de consumo, e as principais categorias de dispêndios. Viu-se que estas últimas são duas, os gastos com medicamentos e os efetuados com mensalidades de planos de saúde. Constatou-se também que as famílias mais pobres têm quase todo o seu gasto com saúde composto por despesas com medicamentos, e que, à medida que estratos progressivamente mais ricos da população são considerados, crescem em importância os dispêndios com planos de saúde. Além disso, verificou-se que a maior parte dos gastos totais em saúde é realizada pelos contingentes mais ricos da população. Nesta se- ção, buscar-se-á analisar o impacto desses gastos no orçamento das famílias, em termos da porcentagem das rendas familiares neles empenhadas, e considerando os estratos de pobreza relativa a que pertencem os membros das famílias.

Existem, essencialmente, duas alternativas metodológicas para empreender esta análise. Uma consiste em simplesmente dividir o gasto total em saúde das famílias pela renda total das famílias, o que pode ser feito para toda a população e individualmente para cada estrato de pobreza relativa. A outra alternativa é calcular, para cada família com ao menos $\mathrm{R} \$ 1,00$ gasto em saúde, o percentual que os gastos em saúde representam da renda domiciliar, e depois obter a média dessa porcentagem em geral e dentro de cada estrato de renda. Neste trabalho somente a última abordagem é apresentada, pois a primeira não permite apreender o peso dos dispêndios em saúde no orçamento doméstico, principalmente no que toca às famílias mais pobres. Isto se deve ao fato de que grande parte das famílias mais pobres não tem gastos com saúde, e, assim, os gastos das que têm ficam diluídos, tornando-se pequenos ante a renda total do estrato.

Parte da ausência de gastos com saúde entre as famílias mais pobres pode ser creditada à 
Figura 4

Porcentagem das despesas totais de saúde de cada décimo da população ordenada de forma ascendente pela renda domiciliar per capita efetuadas com medicamentos (a) e com planos de saúde (b). Regiões metropolitanas, Brasília e Goiânia, 1995/96 - Brasil, 1998.

\section{Figura 4a}

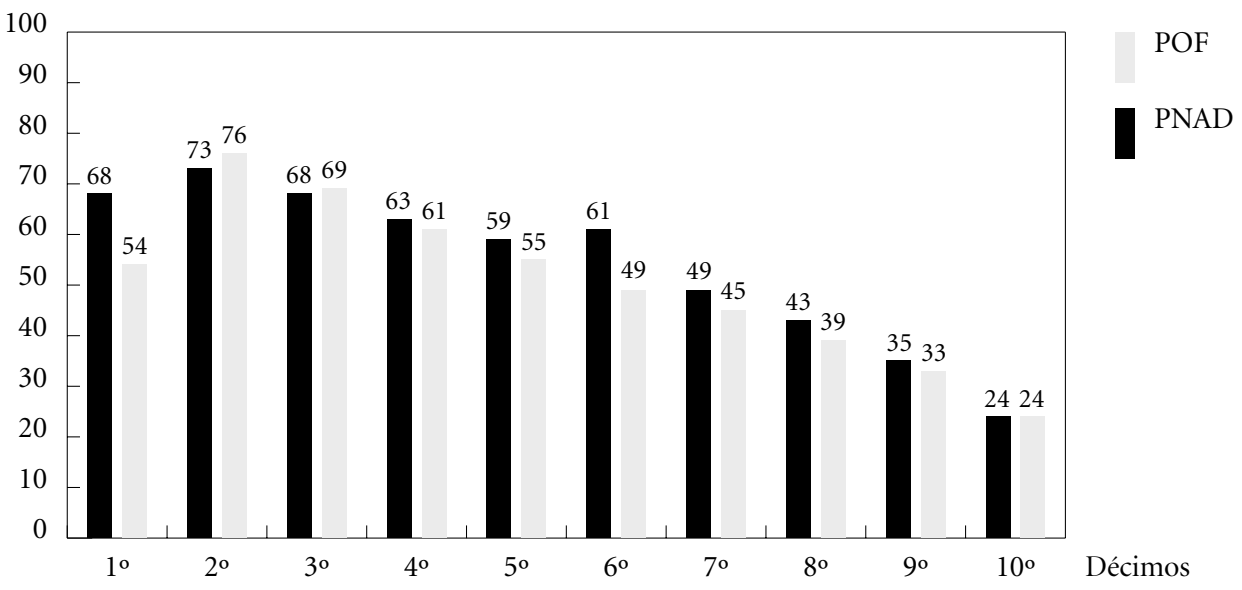

Figura $4 b$

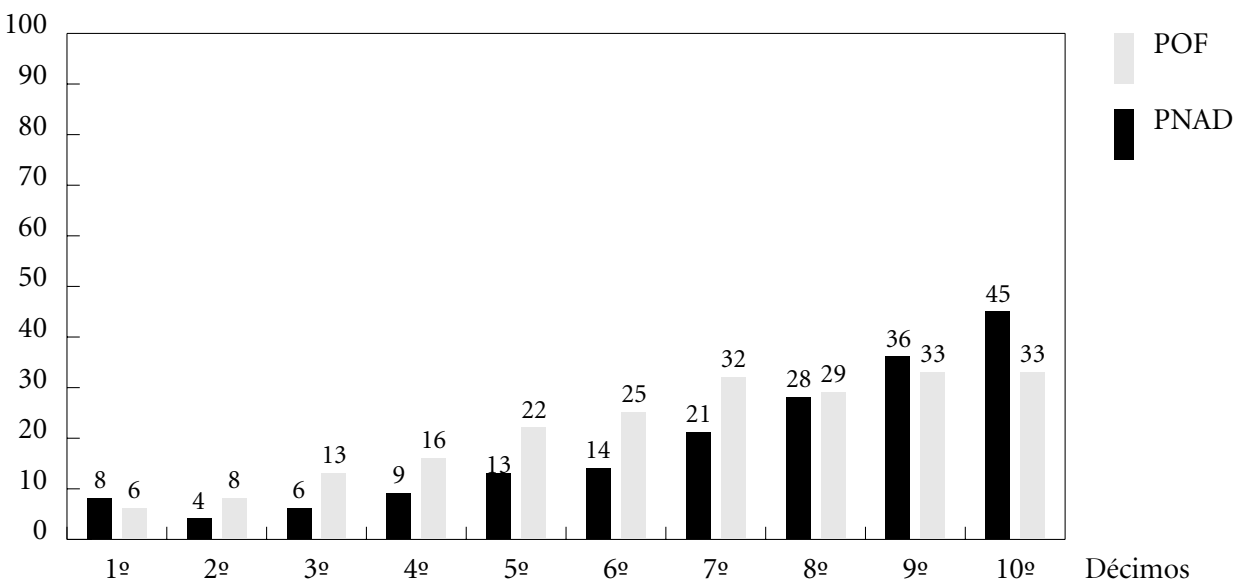

Fonte: IBGE, Pesquisa de Orçamentos Familiares 1995/96, Pesquisa Nacional por Amostra de Domicílios, 1998. Em microdados. 
existência do Sistema Único de Saúde, o SUS. Segundo a PNAD de 1998, nada menos que 95\% das consultas médicas e $93 \%$ das internações hospitalares de pessoas que pertenciam aos $20 \%$ mais pobres da população foram cobertas pelo SUS. Essas coberturas decrescem progressivamente à medida que estratos mais ricos da população são considerados. Ademais, em 48\% dos casos em que um medicamento é receitado para essas pessoas que fazem parte dos $20 \%$ mais pobres, o mesmo é fornecido gratuitamente.

O SUS, portanto, é um fator de peso a ser considerado na explicação da raridade do gasto em saúde dos membros das famílias mais pobres. Entre os 10\% mais pobres, por exemplo, apenas $22 \%$ das pessoas estavam em famílias que haviam realizado gastos com saúde, segundo a PNAD de 1998, enquanto entre os $10 \%$ mais ricos esta proporção era de $89 \%$. Somente $18 \%$ dos $10 \%$ mais pobres residiam em famílias que tiveram dispêndios com medicamentos, sendo de $57 \%$ a fração equivalente entre os $10 \%$ mais ricos. Considerando-se os gastos com planos e seguros de saúde, a situação ganha contornos mais agudos, pois entre os $10 \%$ mais pobres apenas $1 \%$ vivia em famílias que possuíam esse tipo de despesas, proporção que chega a $67 \%$ entre os $10 \%$ mais ricos.

Para evitar a diluição do peso do gasto em saúde, torna-se imperativo considerar somente as famílias que tiveram gastos em saúde para o cálculo da porcentagem da renda domiciliar empenhada nesses gastos. Isso faz com que a quantidade de pessoas em cada estrato se torne diferente, pois, como já dito, entre os mais pobres é maior a freqüência de pessoas em famílias sem gasto. Assim, os estratos deixam de conter décimos da população em sentido estrito, embora as pessoas de cada estrato pertençam aos décimos da população inteira, pois a divisão é realizada antes da seleção dos membros de famílias em que houve gasto.

Outro problema a ser considerado são as famílias que supostamente trabalham com um déficit orçamentário, ou seja, aquelas nas quais os gastos são superiores à renda auferida. Isso pode ser o resultado de várias coisas, de erros de captação das informações a déficits orçamentários efetivos, ou pode ainda representar a mobilização de recursos poupados anteriormente para cobertura de um gasto inesperado. De qualquer forma, as famílias com gasto em saúde superior à renda não serão consideradas nesta parte do estudo, para evitar influências espúrias sobre as médias calculadas. Além disso, o alvo principal do estudo serão os gastos com medicamentos e com planos de saúde, relativamente constantes, e que provavelmente são resolvidos mediante o empenho de parte dos rendimentos regulares das famílias.

Segundo os dados da POF de 1995/96, as famílias que possuíam algum tipo de gasto com saúde empenhavam $8 \%$ de suas rendas neste. A estimativa provida pela PNAD é mais elevada, com em média $12 \%$ da renda da família dedicada aos gastos com saúde em geral. Calculando-se as médias da porcentagem das rendas domiciliares empenhadas nos gastos totais com saúde, obtém-se os resultados representados na figura 5. A partir dele pode-se perceber que de acordo com as estimativas da PNAD os gastos com saúde têm um peso bem maior na renda das famílias do que o averiguado a partir da POF. Convém lembrar, mais uma vez, as diferenças de cobertura, amostragem, e formas de captação da renda e dos gastos nas duas pesquisas, que podem ser responsabilizadas pelas discrepâncias de nível observadas. Porém, o padrão delineado a partir de qualquer uma das fontes é idêntico e muito claro: o peso dos gastos com saúde no orçamento doméstico diminui progressiva e sensivelmente à medida que as famílias dos estratos mais ricos são consideradas.

O mesmo tipo de informação produzido ao se consideraram as famílias que tiveram gastos com medicamentos também mostra discrepâncias de razoável intensidade entre os dados da POF e os da PNAD. Entretanto, as duas pesquisas mostram também o mesmo padrão, e como foi visto que o gasto dos mais pobres é principalmente constituído pela compra de medicamentos, não surpreende o fato de que, para esta parcela da população, a porcentagem da renda domiciliar empenhada com este gasto seja em média quase igual à empenhada com despesas de saúde em geral (Figura 6a). Considerando todas as famílias, independentemente do décimo a que pertenciam seus membros, tem-se que a parcela da renda domiciliar despendida em medicamentos seria em média de $5 \%$, segundo a POF, e de 9\%, segundo a PNAD.

O mesmo padrão observado para os gastos totais e os com medicamentos repete-se para as despesas com planos de saúde, ou seja, é um gasto altamente regressivo. Neste caso, chama-se a atenção para o fato de que nos décimos mais pobres, principalmente nos três primeiros, a quantidade de famílias que possuem esse tipo de gasto é extremamente reduzida. Além disso, no caso da porcentagem média da renda fami- 
Figura 5

Média da porcentagem da renda das famílias empenhada em despesas gerais de saúde por décimos da população ordenada de forma ascendente pela renda domiciliar per capita. Somente famílias com gastos efetivos. Regiões metropolitanas, Brasília e Goiânia, 1995/96 - Brasil, 1998.

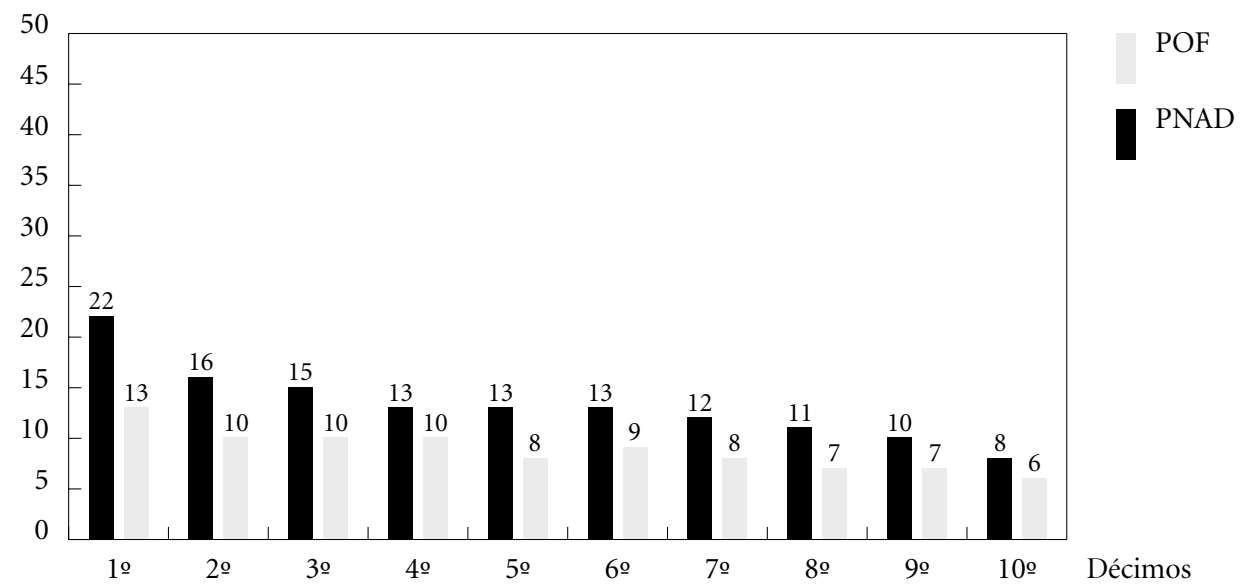

Fonte: IBGE, Pesquisa de Orçamentos Familiares 1995/96, Pesquisa Nacional por Amostra de Domicílios, 1998. Em microdados.

liar gasta em planos de saúde, os dados fornecidos pela PNAD e pela POF são bem mais semelhantes (Figura 6b).

\section{Conclusões}

Os dispêndios efetuados pelas famílias com saúde são o quarto grupo mais volumoso das despesas de consumo familiar, atrás apenas das despesas efetuadas com habitação, alimentação e transporte. Em 1998, estima-se que as famílias gastaram ao menos 37 bilhões de reais com despesas de saúde variadas. Mas a maior parte desses dispêndios é empenhada na compra de medicamentos e no pagamento de mensalidades de planos de saúde. Além disso, também a maior parcela desse gasto é efetuada pelas famílias cujos membros pertencem ao grupo dos $30 \%$ mais ricos da população.

Entre os mais pobres, o gasto em saúde é majoritariamente realizado com a compra de medicamentos. Todavia, à medida que se consideram décimos progressivamente mais ricos da população, cresce a parcela das despesas totais de saúde representada pelos gastos com mensalidades de planos de saúde. Porém, é somente entre os $10 \%$ mais ricos da população que os gastos com plano de saúde são maiores que os efetuados com medicamentos.

Como seria de se esperar, as despesas com saúde, quando existentes, têm um impacto muito maior sobre os rendimentos das famílias mais pobres, o que as caracteriza como altamente regressivas. Obviamente, isso ocorre se elas são consideradas em termos de porcentagem da renda familiar, pois em termos absolutos, essas despesas crescem, pois a maior parte delas é efetuada pelos mais ricos. Porém, dada a desigualdade existente na distribuição da ren$\mathrm{da}$, o peso dos gastos com saúde na renda das famílias que efetivamente realizaram tais gastos, segundo a PNAD, é muito pequeno nas famílias dos mais ricos, embora represente em média quase um quarto do rendimento das famílias cujos membros estão entre os $10 \%$ mais pobres da população.

A despeito das diferenças de nível observadas entre os dados obtidos a partir das duas fontes utilizadas, todas as conclusões descritas nos parágrafos anteriores são validadas tanto pelas informações da POF, quanto pelas da PNAD. Entretanto, os dados da última, talvez pela sua cobertura nacional, e, conseqüentemente, pela 
Média da porcentagem da renda das famílias empenhada em despesas com medicamentos (a) e com planos de saúde (b) por décimos da população ordenada de forma ascendente pela renda domiciliar per capita.

Somente famílias com gastos efetivos. Regiões metropolitanas, Brasília e Goiânia, 1995/96 - Brasil, 1998.

\section{Figura 6a}

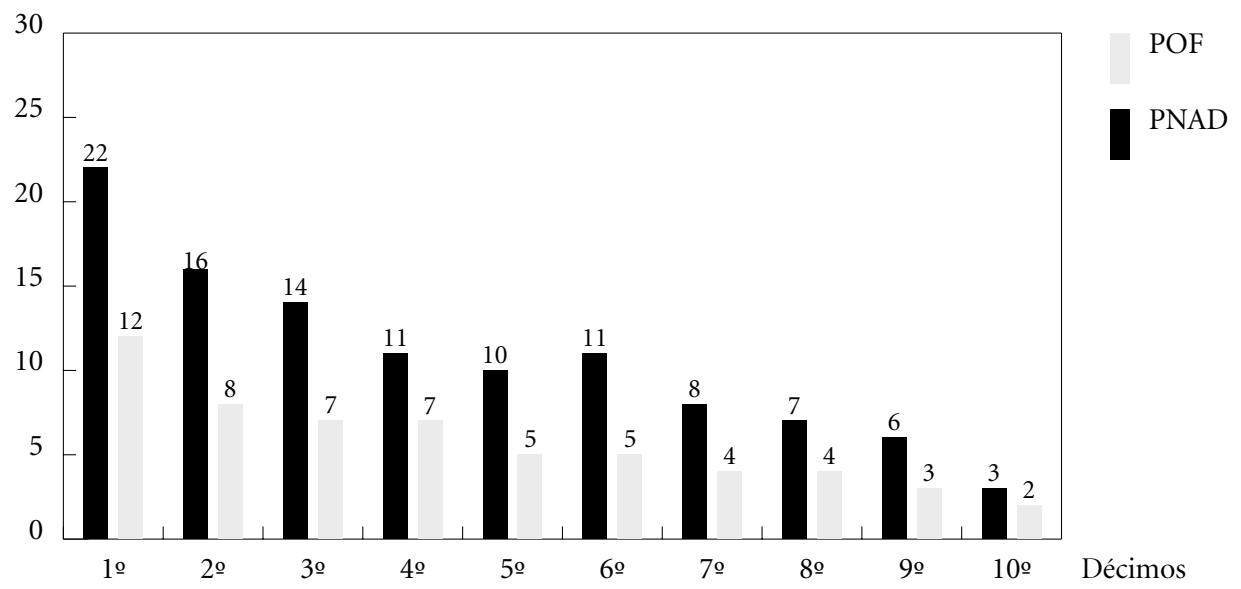

Figura $6 b$

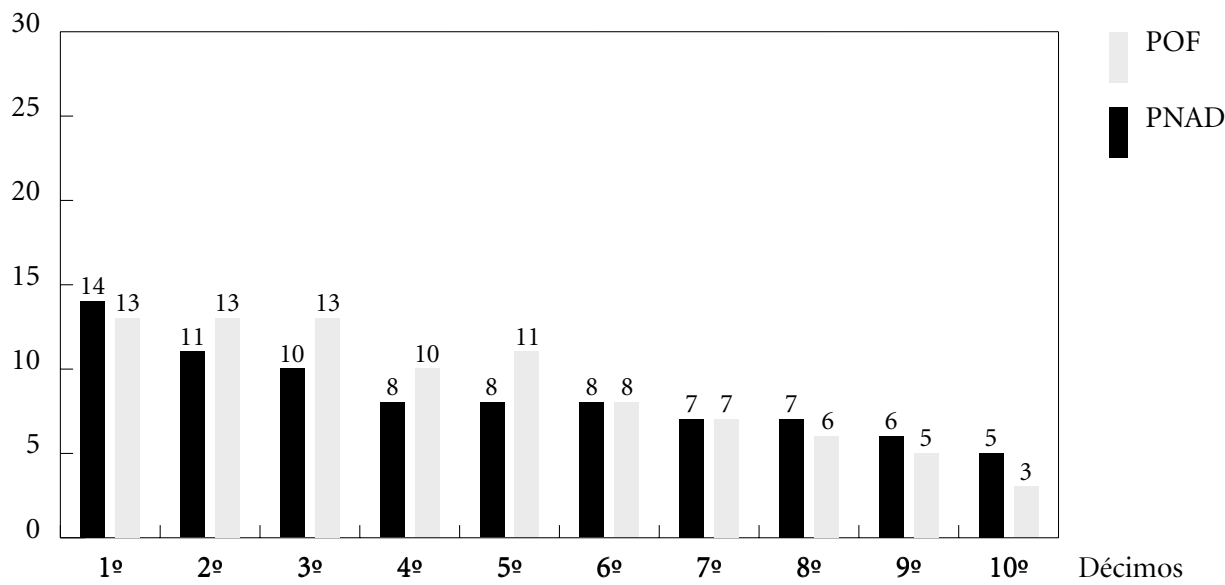

Fonte: IBGE, Pesquisa de Orçamentos Familiares 1995/96, Pesquisa Nacional por Amostra de Domicílios, 1998. Em microdados. 
incorporação de áreas com acesso mais restrito e com menor oferta de serviços de saúde, além de maior pobreza, como as zonas rurais e as urbanas não metropolitanas, delineiam um quadro no qual as diferenças entre os mais pobres e os mais ricos são acentuadas. De qualquer for- ma, tanto o quadro da POF quanto o da PNAD revelam, em última instância, o enorme potencial redistributivo e de impacto sobre a pobreza que têm e podem ter - pois há espaço para que este impacto se amplie - as políticas públicas de saúde de uma forma geral.

\section{Referências bibliográficas}

Barros RP, Mendonça R, Neri M 1995. An evaluation of the measurement of income and expenditure in household surveys: POF versus PNAD. In XVII Encontro Brasileiro de Econometria. Anais 105-29.

Brasil IBGE 1998. Pesquisa Nacional por Amostra de Domicílios 1998, Manual de Entrevista. IBGE, Rio de Janeiro.

Brasil IBGE 1999. Pesquisa de Orçamentos Familiares 19951996. v. 1. IBGE. Rio de Janeiro.

Hoffmann R 1998. A subdeclaração dos rendimentos. São Paulo em perspectiva 2(1):50-4

Medeiros M, Osório RG \& Varella S 2002. O levantamento de informações sobre as famílias nas PNADs de 1992 a 1999. Texto para discussão, 860. IPEA. Rio de Janeiro. Disponível em www.ipea.gov.br.

Rocha S 2000. Estimação de linhas de indigência e pobreza: opções metodológicas no Brasil. In Henriques R (org.) Desigualdade e pobreza no Brasil. IPEA, Rio de Janeiro.

Silveira GF, Tomich F, Vianna SW, Magalhães LCG 2001. Dimensão, características e evolução do gasto familiar com assistência à saúde no Brasil. Nota Técnica. Diretoria de Estudos e Políticas Setoriais do IPEA. Brasília.

Artigo apresentado em 8/8/2002

Aprovado em 6/9/2002

Versão final apresentada em 16/9/2002 